\title{
Motivação e ensino na Gestão Pública: \\ um estudo de caso entre os estudantes de pós-graduação a distância da Univasf do polo de Salgueiro - PE
}

Hesler Piedade Caffé Filho ${ }^{1}$, Neylla Luzia Matias Lima ${ }^{2}$, Pricila Dayane dos Santos Martins ${ }^{3}$

Resumo: O presente estudo teve como objetivo analisar a dentre os alunos de uma pós-graduação na modalidade ead, ofertada pela Univasf, sendo necessário entender que a realização de um curso seja ele presencial ou EAD, possuí diferentes perspectivas para cada indivíduo. O tema motivação e ensino a distância nos abriu um espaço para uma busca de respostas a uma problematização que envolve alunos, a motivação em cursar uma pósgraduação na modalidade à distância e o contato com a gestão pública. Para tanto fez-se uso de questionários no público-alvo, a fim de averiguar a real situação do curso diante da motivação, satisfação e agregação de conhecimento para adequação ao mercado de trabalho. Por fim, pode-se revelar que a pesquisa mostrou resultados satisfatórios no tocante a motivação dos estudantes diante da dificuldades do ensino ead, onde mesmo assim fica visível a necessidade de pequenos ajustes para minimizar a evasão escolar dentro do campo da modalidade ead.

Palavras-Chave: Motivação, Ensino Superior, Gestão Pública.

\section{Motivation and Teaching in Public Management: A Case Study among Distance Graduate Students from Univasf in Salgueiro/PE}

\begin{abstract}
The present study had the objective of analyzing the students of a postgraduate course in the EAD modality, offered by Univasf, and it is necessary to understand that the performance of a course whether it is faceto-face or EAD, has different perspectives for each individual. The theme of motivation and distance learning has opened up a space for a search for answers to a problem that involves students, the motivation to take a postgraduate course in distance learning and contact with public management. For this purpose, questionnaires were used in the target audience, in order to ascertain the real situation of the course in the face of the motivation, satisfaction and aggregation of knowledge to fit the job market. Finally, it can be shown that the research has shown satisfactory results regarding the motivation of the students in the face of the difficulties of teaching ead, where even so it becomes apparent the need for small adjustments to minimize school dropout within the ead modality field.
\end{abstract}

Keywords: Motivation, Higher Education, Public Management.

\footnotetext{
${ }^{1}$ Professor Ms. da disciplina de Comportamento Organizacional na Pós- graduação EAD em Gestão Pública pela UNIVASF. E-mail: prof.caffe@gmail.com

2 Bacharela em Administração pela UFRPE-UAST. Pós-graduanda em Gestão Pública pela UNIVASF. E-maiL: neylla@ hotmail.com.br

${ }^{3}$ Bacharela em Administração pela UFRPE-UAST. Pós-graduanda em Gestão Pública pela UNIASF. E-mail: pricila.dayane@ hotmail.com
} 


\section{Introdução}

Sabendo-se que a motivação é algo difícil de lidar, diante de sua importância num âmbito organizacional este trabalho buscou analisar a importância da motivação entre estudantes de um curso de pós-graduação a distância na área de Gestão Pública, diante de dois pontos básicos: o porquê estes estudantes optaram por cursá-lo e qual a relevância da gestão pública para sua vida e desenvolvimento profissional.

No contexto atual, motivar é uma das principais formas de incentivar os funcionários de uma empresa, ressaltando-se que a motivação pode partir de diversos pontos trazendo benefícios tanto para os alunos como para as instituições públicas, uma vez que a tríade pósgraduação/aluno/organização pode trazer benefícios múltiplos dentro da organização de trabalho, já que funcionários com maior conhecimento geram melhores resultados no ambiente de trabalho. Através de vários estudos revelou-se que o ensino da pós-graduação a distância tem desencadeado mudanças positivas no campo da educação, onde pode-se perceber que diante do contexto social do país esta modalidade de ensino traz uma maior interação e acessibilidade diante da quebra de antigos paradigmas e aumento de possibilidades de estudo mais flexíveis, além de aumento no número crescente do público feminino tanto no mercado de trabalho como nas universidades e pós-graduações (OLIVEIRA, OESTERREICH e ALMEIDA, 2017).

Sendo assim percebe-se que gestão pública é uma área crescente na atualidade diante da dimensão de áreas de atuação, visto que segundo Siqueira e Mendes (2009) apud Carvalho et al. (2015), este campo vem se modernizando e diante das novas implantações governamentais e das demandas sociais as quais a sociedade passou a vislumbrar onde tem-se foco no modismo e implantação de modelos burocráticos gerenciais.

Partindo do pressuposto de que motivar não é algo tão simples, pois lidar com várias pessoas com gostos diferentes requer conhecimento da situação, que neste tocante possam atender as necessidades destes alunos que buscam aperfeiçoamento na área pessoal para agregálo ao ambiente de trabalho visando melhor capacitar-se e atingir cargos mais relevantes no ambiente organizacional, percebe-se que o comportamento humano envolve uma interação situacional durante o trabalho em equipe onde cada aspecto motivacional garante a felicidade pessoal dos alunos, gerando expectativas que vinculam ativamente na realização dos objetivos pessoais. 
O presente estudo se situa na área de Comportamento Organizacional, como um recorte de análise do campo de conhecimento da Administração pública, com enfoque no tipo de motivação utilizada para que os alunos de um curso a distância da Universidade do Vale do São Francisco, com polo na cidade de Salgueiro-PE, permaneçam frequentes no curso e tornem o aprendizado algo de suma relevância diante de sua aplicação no seu ambiente de trabalho. Justifica-se a escolha do referido tema diante da importância deste ao se aplicar a relevância da motivação como meio principal de estimulação de alunos num âmbito interno dentro do campo organizacional que estabelece uma relação pós-graduação/aluno/trabalho.

Como pergunta chave deste artigo estipulou-se a seguinte problemática: "De que maneira a motivação pode influenciar o aluno a permanecer cursando a pós-graduação e como este conhecimento adquirido pode garantir a qualidade de vida no trabalho?". Para tal questionamento teve-se como objetivo geral da pesquisa, analisar as práticas motivacionais e seus efeitos empregados no aluno, assim como o mesmo utiliza-se das práticas do curso para sua atuação no ambiente externo, levando seu conhecimento adiante.

\section{Organização e Motivação: conceituação básica}

Pode-se conceituar organização como um conjunto de pessoas que, além de objetivarem coisas em comum, ainda desenvolvem uma forma de divisão de trabalho onde todos os integrantes buscam através de metas estabelecidas alcançarem os objetivos da empresa (CHIAVENATO, 1982).

Este tipo de abordagem gera um sistema progressivo de previsões que são tidos como resoluções dos conflitos existentes protegendo uma resolução eficiente de qualquer problemática interna além de visar traçar alternativas para motivar a todos os envolvidos no processo organizacional. A motivação é tida na atualidade como uma forma nova de estipulação de resultados nas organizações, visando que o grande desafio ainda é a necessidade de novas ferramentas de gestão aplicadas à motivação para adquirir diferencial competitivo diante dos concorrentes (FILHO et al. 2009).

A avaliação destes resultados visa os resultados obtidos através da implantação da motivação na forma de gerir uma empresa pública ou privada, visto que uma empresa é tida como uma organização e depende da eficiência e na equidade dos empregados e de todos os 
envolvidos no processo organizacional para desempenhar os resultados almejados com eficácia, uma vez que a existência de diversos tipos de métodos para garantir a motivação são baseados em modelos e utilizados de acordo com a organização e dos objetivos e metas a serem projetados segundo Montana (1999, p. 2003) apud Lima et al. (2014).

\section{Gestão de Pessoas e motivação}

A atividade de gerir pessoas dentro do meio organizacional não é muito fácil de ser aplicado, uma vez que muitas organizações classificam suas equipes como mensalistas e honoristas (CHIAVENATO, 1999). Ressalta-se que neste estudo os atores envolvidos são os alunos de um curso ead ofertado pela Univasf, que tendem a estarem motivado e que optam por esta modalidade para obter o título de especialista na referida área. Porém, só esta alternativa não basta para entender a permanência dos mesmos nesta pós-graduação diante das dificuldades diárias e do desdobramento entre trabalho, família lazer e logística.

Sendo assim, é necessário revelar que a motivação deve ser aplicada como ponto de tensão que leva um indivíduo qualquer a satisfazer suas necessidades básicas, dentro de um ciclo motivacional onde o organismo humano tem um equilíbrio psicológico, segundo a teoria de Lewin que pode apenas suprir ou desencadear o rompimento do estímulo básico. Provocando assim um comportamento de estímulo de sobrevivência com descarga tensional (CHIAVENATO, 2003, 119). O que remete-se a observar que a aluno tem que estar preparado para lidar com todas as atividades pré-elaboradas e dimensionadas a realidade dos cursos EAD - Educação a Distância, enfatizando-se que todos tem suas limitações e que apenas a motivação é capaz de suprir as necessidades individuais projetando ganhos coletivos.

\section{Ensino EAD e Motivação: aplicações na qualidade de vida no trabalho.}

A qualidade de vida no trabalho é um influenciador motivacional não apenas por das condições necessárias de trabalho e educação, mas também para desenvolver potenciais talentos através de estímulos simples e que deveriam ser explorados tanto pelos gestores da atualidade como pelos professores, líderes, gestores e etc. 
Este tipo de melhoria focaliza-se na sobrevivência de relações hábeis e justapostas a ambientes limpos, ergonomicamente saudáveis que proporcionam diminuição de esforços físicos desnecessários com intuito de obtenção de melhores resultados através de funcionários satisfeitos. Sendo este um ponto chave na área da EAD, uma vez que este tipo de ensino não apresenta estrutura física de ensino sendo realizado em ambientes virtuais, porém este ambiente deve ser de fácil acesso e entendimento para que o aluno não se sinta excluído dos demais por falta de prática com acesso a computadores, notebook, tablet, etc. Mas como todo ensino as instituições que oferecem cursos EAD, tem por obrigação oferecer sedes físicas para que os alunos em algum momento do curso conheçam seus colegas, professores e tutores onde segundo Vieira (2011, p. 31):

Em detrimento da dialogicidade, - aqui entendida como interação e construção conjunta dos conhecimentos, - os procedimentos, geralmente empregados na modalidade EaD, valorizam a exposição de temas sequenciais e o ambiente virtual de aprendizagem priorizando o cumprimento dos conteúdos programáticos.

É aí que surge o ponto chave da interação entre a EAD e a qualidade de vida no trabalho, pois seja qual for à atividade desempenhada está ligada fortemente ao nível de motivação do funcionário dentro da organização educacional. Segundo Moreti e Treichel (2003), a análise QVT tende a reorganizar a estrutura de uma empresa visto que a satisfação tem como foco principal nos resultados almejados diante das trocas de relacionamentos internos e sua motivação, onde:

\footnotetext{
Entendendo-se a partir deste conceito que o trabalho pode dignificar o homem, porém para que isto aconteça é necessário um desenvolvimento físico e psíquico de esforço pessoal que resulta no desempenho da atividade realizada. Observa-se que pessoas com melhor qualidade de vida no trabalho desempenham melhores funções e tem nível de motivação excelente, além de ter atitudes marcantes e auto grau de persuasão na equipe organizacional (p.32).
}

Sendo relevante analisar a relação entre a qualidade de vida no trabalho ou modelo QVT, onde Freitas e Souza (2009, apud LAWLER 2005), acreditam que este modelo tende a motivar os estudantes em questão através de identificação de formas de convivência saudável e eficaz, uma vez que é tida como dos aspectos de suma importância no ambiente organizacional, gerando o bem-estar dos alunos no ambiente interno durante a realização de suas tarefas. 
O ensino EAD se mostra favorável nas organizações da atualidade, que buscam cada vez mais profissionais capacitados e em constantes atualizações diante da ideia de inserção de cursos EAD, que é tida como uma das propostas da atualidade para que pessoas de todos os lugares do mundo possam minimizar suas limitações e difundir as necessidades para crescer no mercado de trabalho.

\section{Dificuldades encontradas no ensino Ead}

Após entender sobre o que é motivação, a dificuldade de gerir pessoas e a questão da educação ead e suas aplicações é necessário também enxergar que como toda modalidade educacional, esta apresenta algumas limitações e é através disso que se percebe a existência de pontos negativos e a necessidade de transformá-los em oportunidades. Sendo assim, Lima, Araujo e Pinto (2014), explanam que o cenário educacional na modalidade EAD ainda apresenta alguns pontos a serem melhorados, diante das dificuldades tanto dos educadores como dos alunos. Onde segundo estes mesmos autores:

\footnotetext{
Considerando as características dos alunos conectados, acredita-se que seja importante que o professor da EAD organize os encontros presenciais para prender a atenção desse público, usando recursos didáticos como: recursos audiovisuais e discussão em sala de aula de forma dinâmica, promovendo debates, por exemplo, como forma de prender a atenção dos alunos ao conteúdo que está sendo discutido e estimulá-los a comparecer na sala de aula virtual, bem como discutir temas que sejam úteis para a sua prática profissional, no presente ou no futuro (p.42).
}

Sendo neste aspecto, necessário observar que apesar da facilidade de se estudar em casa, não existe necessariamente motivação sem que sejam introduzidas técnicas motivacionais e recursos para estimular os alunos. Tendo-se assim uma visão de que sem motivação muitos apenas iniciam os cursos ead de ensino superior, mas não chegam a terminá-los, o que evidencia a quebra de conhecimento e a pouca efetividade de ensino sem motivação.

Paula et al. (2017), relatam que através de seus estudos muitos estudantes repercutem a ideia de que as participações durante a formação no ensino tendem a ser direcionadas para influenciar os alunos a desenvolver pensamento critico e posteriormente a possibilidade de aplicá-lo no campo da administração pública. O que remete a acreditar que os cursos ead devem seguir certo grau de burocrática diante das especificações do mesmo, porém direcionar o ensino 
de uma forma a de flexibilizar diante das limitações dos estudantes além de analisar continuamente todos os pontos negativos para diminuir as problemáticas da falta frequente de encontros presencias com professores para esclarecimento de dúvidas diariamente versus maior flexibilidade de rotinas diárias de estudo.

\section{Método}

Para realização desta pesquisa primeiramente fez-se um levantamento bibliográfico sobre a referida temática, onde se obteve um conhecimento teórico de suma importância para a averiguação dos dados a serem levantados. Posteriormente, fez-se um estudo de natureza qualitativa onde segundo Günther (2006), neste tipo de natureza pode-se ter uma melhor realidade dos fatos por buscar informações verídicas e de qualidade além de coletar dados mais complexos e de fácil entendimento. Sendo necessário enquadrar-se a pesquisa como qualitativa - exploratória visando segundo GIL (2007) apud GERHARDT e SILVEIRA (2009), familiarizar-se com a problemática a fim de se construir uma realidade e buscar soluções através dos dados explorados para averiguar e propor alternativas para sanar a problemática existente.

A pesquisa teve como público alvo os estudantes do curso de pós-graduação em Gestão Pública na Univasf - Salgueiro, onde foi necessário aplicado um questionário virtual que continha 18 questões semi-estruturadas elaborados pelos pesquisadores, dentre os alunos deste polo, para análise situacional do grau de motivação dos mesmos e averiguação da satisfação com o curso além da aplicabilidade destes conhecimentos dentro do ambiente de trabalho.

Visando revelar que o tratamento dos dados obtidos serão apresentados a seguir através de gráficos e observações, ressaltando-se que as análises das respostas serão de suma importância para adquirir um feedback da real situação com relação aos objetivos do curso e dos alunos do mesmo criando-se assim elo entre o desejável e o real nível de motivação obtido para aplicabilidade dos conhecimentos teóricos no campo organizacional, uma vez que os alunos deste referido curso tem formações em áreas diferentes e trabalham em diversas esferas públicas. Contudo, explana-se que o conhecimento adquirido ao longo do curso pode beneficiar os alunos no mercado de trabalho, uma vez que a área de gestão pública trás benefícios múltiplos para toda a sociedade brasileira. 


\section{Análise e Discussões}

A aplicação do questionário foi feita através de meio eletrônico "Google Formulários", dentre os alunos do curso de pós-graduação a distância do polo Salgueiro-PE, visando-se maior comodidade para o público-alvo diante de suas rotinas.

Neste meio, percebeu-se que dentre o público-alvo em questão que contribuíram para o levantamento de dados uma relativa porcentagem de $75 \%$ dos entrevistados eram do sexo feminino e apenas $25 \%$ são do sexo masculino, sendo importante em uma primeira observação refletir sobre estas porcentagens diante do grande público feminino que está cada vez mais presente no mercado de trabalho e buscando aperfeiçoamento e quebra de barreiras.

Posteriormente viu-se que dentre os entrevistados esta porcentagem feminina no campo em questão já é algo estudado por diversos autores, além de entender que estes entrevistados já têm conhecimentos pré-elaborados e matizados diante da idade, uma vez que ocorre uma variância entre 25 a 54 anos o que revela que os entrevistados já tiveram experiência com outras formas de ensino e já tem certa carga de conhecimento, buscando uma melhor alocação de informações para obter crescimento profissional tanto na área que atuam como nas áreas que pretendem atuar. Deve-se expor também a questão sobre a formação superior, onde observouse uma certa diversidade em áreas correlacionadas com a Administração Pública, onde 62,5\% tinham curso superior em Administração, 25\% em Ciências Econômicas e 12,5\% em Pedagogia.

Visou-se neste meio averiguar se estes faziam parte do mercado de trabalho, para se explanar como o curso em questão poderia ajudar os mesmos durante o desenvolvimento de suas atividades de trabalho, diante da aplicabilidade de conhecimentos teóricos na administração pública. Onde após este primeiro dividiu-se as perguntas em quatro grupos básicos de questões: a análise do curso pelos alunos; o grau de motivação do curso por parte dos alunos; a motivação e os pontos negativos na visão dos alunos; e, por fim, aspectos apontados como melhora diante da realidade dia-a-dia dos alunos. Abaixo seguem as reflexões obtidas após aplicação de questionários diante dos grupos de averiguação. 
- A análise do curso:

Neste tópico, evidenciou-se a participação dos alunos na esfera pública, onde se percebeu que $62,5 \%$ dos entrevistados trabalham na área pública, enquanto que os 37,5\% restantes não, sendo o curso visto como uma ponta-pé inicial para formação crítica através da agregação de conhecimento e para formação de possíveis carreiras na esfera pública.

Os estudantes alegaram que as disciplinas ofertadas no curso foram importantes na sua rotina de trabalho, visto que a teoria é relevante no momento de colocar em prática algumas atividades, onde $87,5 \%$ concordaram com tal afirmativa e $12,5 \%$ classificaram como indiferente.

Sabendo-se que o curso frequentado por esses alunos se encontra em uma plataforma digital e os problemas enfrentados nessa modalidade de ensino a distância, foi questionado o posicionamento deles a cerca do curso diante do grau de satisfação dos mesmos com relação à pós-graduação, onde se percebe a seguinte análise:

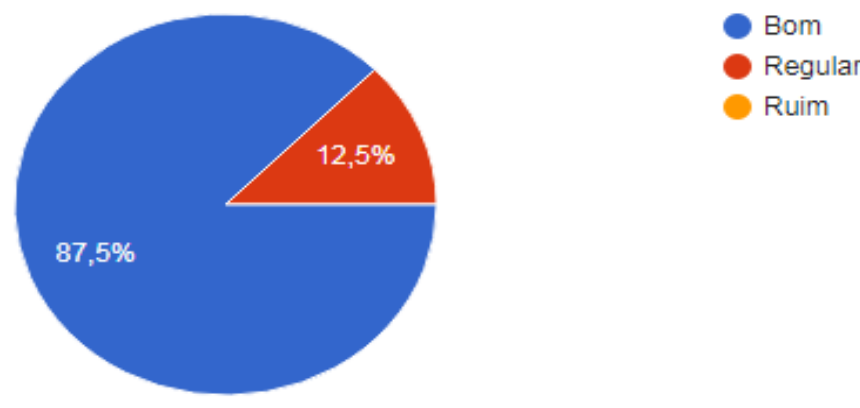

Gráfico 1: Classificação da Pós-graduação na visão dos alunos.

Fonte: Autores.

Na relação do gráfico acima $87,5 \%$ responderam que o curso é bom, enquanto $12,5 \%$ classificaram como regular. Sendo necessário avaliar estes resultados para se saber o porquê de estes estudantes que classificaram o curso como regular sente este certo grau de insatisfação, 
uma vez que numa análise geral esta porcentagem é tida como alta diante da flexibilidade de estudo dos cursos ead.

A qualidade de vida no trabalho (QVT) está amplamente ligada as práticas desenvolvidas ao desempenhar seu trabalho, podendo estas possuírem bases ensinamentos teóricos, assim quando questionados sobre a relação QVT/curso, se no caso o curso contribuiu significativamente para uma melhora na sua QVT apenas 37,5\% concordaram que sim, 25\% evidenciaram que não houve melhora alguma e 37,5\% acharam indiferente a relação de um com o outro. Onde esta reflexão remete-nos a explanar que ainda existem alguns pontos a serem melhorados para posicionar o curso em questão com a realidade da administração pública do país.

\section{- Grau de motivação:}

Neste quesito foram pontuadas algumas opções para que os alunos pudessem indicar porque escolheram cursar esta pós-graduação, visto que seria interessante averiguar diante da opinião dos estudantes, onde obteve-se a seguinte análise:

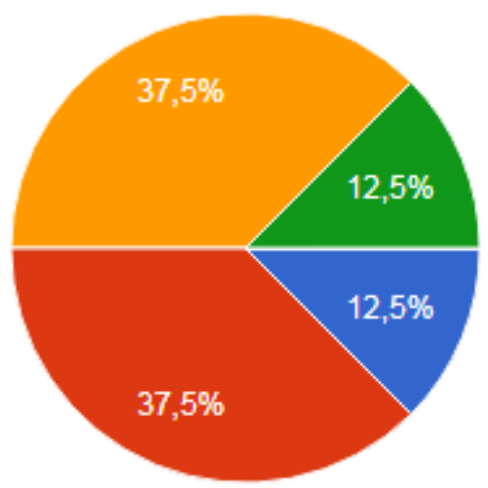

TRABALHo na ÁREA E PRECISAVA ADQUIRIR MAIS CONHECIMENTO.

GOSTO DA ÁREA, POR ISSO RESOLVI CURSA-LÁ

É UM BOM CURSO E ISSO ME INTERESSOU.

APENAS O TÍTULO DE ESPECIALISTA

FALTA DE OPÇÃo

Gráfico 2: Motivos para cursar a pós-graduação em gestão pública na visão dos estudantes.

Fonte: Autores

Dentre os alunos ressalta-se que 37,5\% responderam gostar da área e por isto revolveram cursá-la, outros $37,5 \%$ disseram ser um bom curso e isso os interessou, $12,5 \%$ trabalham na área e precisam adquirir mais conhecimento e os outros 12,5\% resolveram cursar apenas pelo título de especialista. Sendo importante também ressaltar que houve uma única opção que não 
houve posicionamento de nenhum dos estudantes, a falta de opção de estudo, sendo assim logicamente pode-se entender que o curso em questão é visto de forma interessante para o público de estudantes desta área, tanto na dimensão logística como na área relativa à administração pública.

Quanto a questão “expectativas x necessidades”, a cerca do curso, 87,5\% classificaram de forma positiva e 12,5\% negativa. Quando questionados sobre o desempenho no curso cerca de $62,5 \%$ responderam que era bom e $37,5 \%$ regular. A motivação foi abordada como uma pontuação onde os entrevistados respondiam o seu grau em relação ao curso numa escala de 0 a 10, onde 0 a 3 era classificado como ruim, 4 a 6 mediano e 7 a 10 ótimo, sendo apresentados abaixo dos dados tabulados:

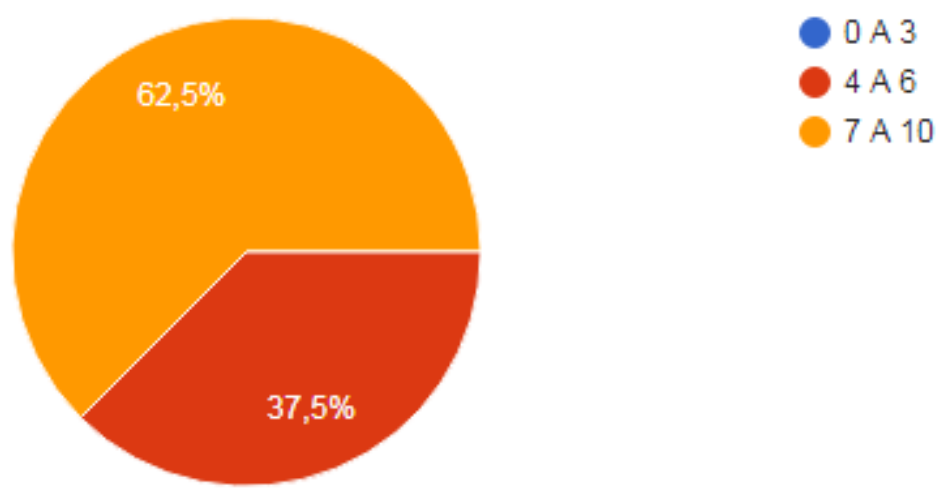

Gráfico 3: Grau de Motivação que o na visão dos estudantes. Fonte: Autores

Percebe-se que a grande maioria dos estudantes $(62,5 \%)$ classificam o curso como ótimo, estando satisfeitos e motivados a permanecer cursando-o para atender as suas necessidades profissionais e pessoais. Já 37,5\% o classificaram como regular, sendo que esta porcentagem apesar de não ser maioria tende a necessitar de uma avaliação posterior e consequentemente um acompanhamento visto que diante do grau de motivação intrínseca dada pelos mesmos o curso ainda tende a introdução de técnicas que melhor se englobem a realidade das rotinas diárias como será exposto no bloco de questões a seguir. 
- Motivação e pontos negativos na visão dos alunos

Neste penúltimo bloco de questões teve-se o intuito de averiguar se o aluno se sentiu motivado, onde a maioria (cerca de $75 \%$ ) respondeu que sim e apenas $25 \%$ queixa-se de algumas falhas que diminuíram sua motivação inicial durante o período de estudo do curso, como mostra o gráfico abaixo:

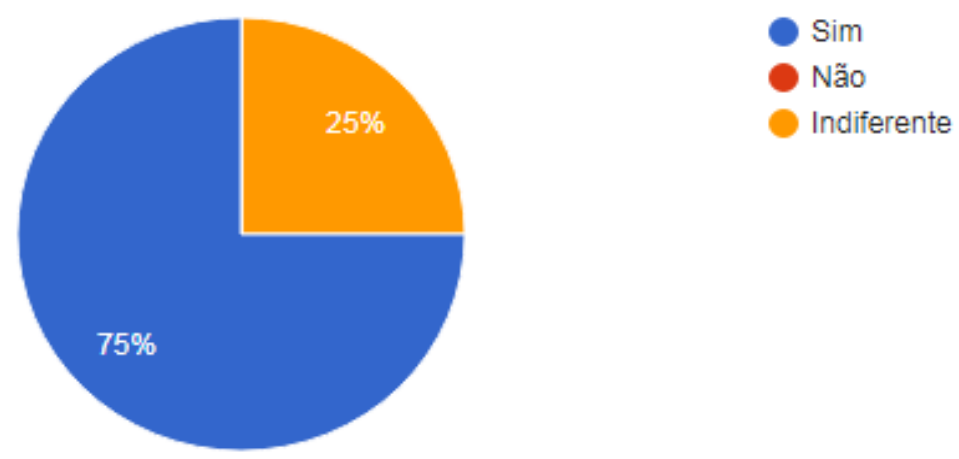

Gráfico 4: Você sentiu-se motivada durante o curso?

Fonte: Autores

Para elencar ainda mais os pontos negativos que diminuíram a motivação no decorrer do curso, foi criada uma pergunta aberta onde os estudantes puderam expor seu ponto de vista, onde os principais pontos citados foram:

- A falta de orientação por parte de alguns professores;

- Orientação do TCC, e contato direto com os professores difícil de ter;

- Não ter afinidade com o ambiente virtual, o modelo EAD causou dificuldade, além também do tempo para respostas nesse ambiente;

- Por ser modelo EAD, faltou interatividade entre a turma;

- Pouca flexibilidade em algumas disciplinas;

- Repetição na forma de realização das atividades;

- Não ter direito a escolher o orientador e o tema do TCC. 


\section{- Aspectos apontados como melhora diante da realidade dia-a-dia dos alunos}

Para tentar entender um pouco mais sobre as necessidades dos entrevistados, questionou-se sobre de que forma a pós-graduação em gestão pública poderia lhes ajudar diante do seu crescimento profissional, onde obteve-se os seguintes pontos:

\footnotetext{
"Me ajudou a adquirir mais conhecimento sobre a área pública”; entrevistada 1, 25 anos.

"Melhorei meu desenvolvimento no ambiente de trabalho"; entrevistado 3, 32 anos.

“Agregação de conhecimento para concursos públicos”; entrevistado 4, 26 anos.

"Um melhor entendimento de procedimentos públicos, que trouxeram entendimento sobre o processo de algumas atividades no trabalho”; entrevistada 8, 29 anos.
}

Diante destas informações é nítido que os alunos deste curso de pós-graduação à distância ofertado pela Univasf, trás um foco nas necessidades do mercado de trabalho no campo da administração pública, e que mesmo diante das dificuldades existentes ajuda a enfatizar que apesar de todo o conhecimento adquirido nas universidades os estudantes ainda tendem a se especializarem para objetivar melhores cargos e salários no campo publico além de ajudá-los a entender melhor a sua percepção sobre as problemáticas sociais da população brasileira.

Por fim, ponderou-se aos alunos alternativas que visassem um melhor englobamento para diminuir o grau de insatisfação do curso e tentar uma melhor adequação do mesmo com as possíveis turmas posteriores, onde revelou-se as seguintes alternativas:

- Maior auxilio por parte dos professores no esclarecimento de duvidas e maior interação nos chats;

- Com relação à equipe gestora, teve-se um grande acolhimento por parte do coordenador e dos seus auxiliares, além de tutoria excelente, porém o excesso de matéria e falta de explicações em alguns materiais utilizados deixam dúvidas que deveriam ser retiradas através de um feedback semanal com os professores após avaliações;

- Aumento nos encontros presenciais para melhor entrosamento entre turma e professor, além de claro construir redes de relacionamentos para aumentar a participação nos fóruns de discussões; 
- Atividades mais focadas na realidade e não apenas em bases teóricas;

Com isso, projeta-se que estas podem ser algumas alternativas viáveis e praticas para aumentar não só a motivação durante o curso como também a minimizar evasão escolar e aumento da priorização da relação organização/aluno.

\section{Considerações Finais}

O presente estudo fez uma tentativa, através de uma pesquisa de responder tal problemática: Como a motivação poderia influenciar o aluno de tal forma a permanecer cursando a pós-graduação com o intuito de adquirir conhecimento para uma melhora na sua qualidade de vida no trabalho. Diante disto tratamos de analisar a formação do aluno, o ambiente de trabalho no qual o mesmo está inserido, a fim de correlacioná-lo com a realidade da pós-graduação em Gestão pública e com a forma que ela impacta na QVT, ainda foram analisados os pontos negativos do curso EAD, bem como o grau de motivação que o aluno estaria sentindo diante das dificuldades enfrentadas nessa modalidade de ensino.

Fez-se claro que o curso possui uma boa base de ensino, onde $87,5 \%$ dos entrevistados disseram ser um bom curso, logo pode-se ressaltar a importância do conhecimento teórico no dia a dia, seja no ambiente de trabalho ou em contato direto com algum órgão público. Com isto ficou evidenciado que apesar da modalidade ser ensino a distância, a grande maioria dos alunos sentem-se motivados a adquirir conhecimento, visando poder utilizar no seu ambiente trabalho, assim como citado por alguns que através dos estudos conseguiram um melhor entendimento acerca dos procedimentos realizados para execução de suas atividades diárias. Outros disseram sentir-se motivados, pois agregariam conhecimentos para possibilidades futuras, ou seja, conhecimento para concursos, visando adentrar na carreira pública.

Outro ponto essencial diante da problemática a ser debatida, foi os pontos negativos do curso, que no caso deveriam ser classificados como pontos a melhorar, visto que não atrapalharam o desenvolvimento do aluno, apenas causaram pequenos impasses que poderiam ser evitados caso levados em consideração no decorrer do período de curso dos entrevistados, tais quais a interatividade que deixa a desejar, bem como a falta de orientação na reta final do curso e a repetição na forma de realização de atividades. 
Através da entrevista fica em destaque que o curso de Gestão de Pública mesmo na modalidade a distância possui características boas e disciplinas que ajudaram os entrevistados a entender procedimentos, assim como ajuda-los na rotina de trabalho para aqueles que já atuam na área pública. Portanto o que se faz necessário são apenas alguns ajustes para que o mesmo tenha uma melhora significativa a fim de reter mais alunos.

\section{Referências:}

CARVALHO, P. A. S.; TORRES, K. A.; BORBA, E. L.; MARTINS, P. L. ANALISE DA GESTÃO DE PESSOAS NA ADMINISTRAÇÃO PÚBLICA: UM ESTUDO DE CASO. Disponível em: https://www.aedb.br/seget/arquivos/artigos15/33022365.pdf.

CHIAVENATO, Idalberto. Introdução à teoria geral da administração: uma visão abrangente da moderna administração das organizações / Idalberto Chiavenato - 7. ed. rev. e atual. - Rio de Janeiro: Elsevier, 2003 - 6' reimpressão.

Paulo: McGraw-Hill, 1982.

I. Administração de Empresas. Uma abordagem contingencial. São

I. Gestão de Pessoas: o novo papel dos recursos humanos nas organizações. Rio de Janeiro: Campus, 1999.

FILHO, C.C.M.; FERREIRA, E. P.; SALGADO, F. H. M.; BARUEL, L. G.; LIMA, W. C.; MASCARENHAS, C. C. MOTIVAÇÃO: UMA FERRAMENTA DE GESTÃO NAS ORGANIZAÇÕES. $\quad$ Disponível em http://www.inicepg.univap.br/cd/INIC_2009/anais/arquivos/RE_0102_0412_01.pdf.

FREITAS, A. L. P.; SOUZA, R. G. B. Um modelo para avaliação da Qualidade de Vida no Trabalho em universidades públicas. Universidade Estadual do Norte Fluminense (UENF), Mestrado em Engenharia de Produção Campos dos Goytacazes, Rio de Janeiro, Brasil. Recebido: Agosto, 2008 / Aceito: Agosto, 2009. Disponível em: http://www.academia.edu/4143177

/Qualidade_de_Vida_no_Trabalho_do_tecnicoadministrativo_em_IES_publicas_uma_analise _exploratoria.

GÜNTHER, H. Pesquisa Qualitativa Versus Pesquisa Quantitativa: Esta É a Questão?. Disponível em: http://www.scielo.br/pdf/\%0D/ptp/v22n2/a10v22n2.pdf.

LIMA, M. A. A.; AS, E. M. O.; PONTO, A. C. PERFIL E DIFICULDADES DO ALUNO DA EAD: O CASO DO CURSO DE BACHARELADO DE ADMINISTRAÇÃO PÚBLICA. Disponível em: http://esud2014.nute.ufsc.br/anaisesud2014/files/pdf/128198.pdf. 
LIMA, N. L. M.; NASCIMENTO, V. N. S.; MARTINS, P. D.; MENESES, E. R. A.; PEREIRA, M. E. S.; QUEVEDO, A. P. F. MOTIVAÇÃO NAS ORGANIZAÇÕES: UM ESTUDO DE CASO SOBRE A MOTIVAÇÃO DOS ESTUDANTES DE ADMINISTRAÇÃO DA UNIVERSIDADE FEDERAL RURAL DE PERNAMBUCO (UFRPE), DA UNIDADE ACADEMICA DE SERRA TALHADA -PE. Disponível em: http://www.convibra.com.br/upload/paper/2014/34/2014_34_9229.pdf.

MORETTI, S.; TREICHEL, A. Qualidade de vida no trabalho x Auto Realização Humana. Instituto Catarinense de Pós-Graduação - www.icpg.com.br. Disponível em: http://www.posuniasselvi.com.br/artigos/rev03-12.pdf.

OLIVEIRA, P. R.; OESTERREICH, S. A.; ALMEIDA, V. L. Evasão na pós-graduação a distância: evidências de um estudo no interior do Brasil. Disponível em : http://www.scielo.br/scielo.php?pid=S1517-97022017005010105\&script=sci_arttext.

PAUlA, H. C.; LIMA, M. A.; OLIVEIRA, L. B.; BRITO L. M.; A PARTICIPAÇÃO DOS ALUNOS DO CURSO A DISTÂNCIA DE ADMINISTRAÇÃO PÚBLICA DA UFOP NA GESTÃO PÚBLICA. Disponível em: http://seer.ufrgs.br/index.php/renote/article/view/75158.

VIEIRA, L. A. ENTRE O REAL E O VIRTUAL: A EDUCAÇÃO A DISTÂNCIA (EaD) COMO ESPAÇO PARA O EDUCAR (APRENDER E ENSINAR) PELA PESQUISA. Disponível em: http://www4.pucsp.br/gepi/downloads/RESUMO_DISSERTACOES_GEPI/2011_TESE_LE OCILEA.pdf.

Como citar este artigo (Formato ABNT):

CAFFÉ, Hesler Piedade; LIMA, Neylla Luzia M.; MARTINS, Pricila Dayane dos S. Motivação e ensino na Gestão Pública: um estudo de caso entre os estudantes de pós-graduação a distância da Univasf do polo de Salgueiro - PE. Id on Line Rev.Mult. Psic., 2018, vol.12, n.40, p.680-695. ISSN: 1981-1179.

Recebido: 02/04/2018

Aceito 03/04/2018 